\title{
PROCESSO FORMATIVO DE PROFESSORAS DA EDUCAÇÃO INFANTIL: ANALISANDO AÇÕES SOBRE A LOCALIZAÇÃO E PERCEPÇÃO DO ESPAÇO COM BEBÊS
}

\author{
SANDRA APARECIDA FRAGA DA SILVA' \\ ANDRESSA WIEDENHOFT MARAFIGA ${ }^{2}$ \\ ANEMARI ROESLER LUERSEN VIEIRA LOPES ${ }^{3}$
}

FORMATIVE PROCESS OF TEACHERS OF CHILDHOOD EDUCATION: ANALYZING ACTIONS ON LOCATION AND PERCEPTION OF SPACE WITH BABIES

\section{RESUMO}

Este trabalho discute o processo formativo docente com base na análise de ações, abrangendo localização e percepção do espaço em uma turma de Berçário II. As ações decorrem de um curso de extensão sobre Geometria e movimentos lógico-históricos de seus conceitos, envolvendo licenciandas e professoras. Utiliza-se a abordagem teórico-metodológica da Atividade Orientadora de Ensino, atrelada à Teoria da Atividade. 0 processo formativo envolveu estudo do movimento lógico-histórico dos conceitos de localização e percepção espacial como conhecimentos importantes para 0 ensino de Geometria. Conclui-se que a organização do ensino de Geometria para a Educação Infantil deve primar pela geometria sensorial, considerando a atividade principal da criança, o brincar, o que pode ser desencadeado por meio de um movimento que promove 0 desenvolvimento das crianças e propicia aprendizagens ao professor. Identifica-se, ainda, a necessidade de discussões sobre estudo de conceitos geométricos para a organização do ensino de geometria na infância.

Palavras-chave: Educação Infantil. Formação de professores. Geometria. Atividade Orientadora de Ensino. Teoria Histórico-Cultural.

\section{ABSTRACT}

This paper discusses the teacher training process based on the analysis of actions, covering location and perception of space in a class in Nursery II. The actions result from an extension course on Geometry and logical-historical movements of its concepts, involving undergraduates and teachers. The theoretical-methodological approach of the Teaching Guiding Activity is used, linked to the Activity Theory. The formative process involved the study of the logical-historical movement of the concepts of location and spatial perception as important knowledge for teaching Geometry. It is concluded that the organization of geometry teaching for Early Childhood Education must excel in sensory Geometry, considering the child's main activity, playing, which can be triggered by means of a movement that promotes the development of children and provides learning to the teacher. It is also identified the need for discussions on the study of Geometric concepts for the organization of teaching geometry in childhood.

Keywords: Early Childhood Education. Teacher training. Geometry. Teaching Guidance Activity. Historical-Cultural Theory.

\footnotetext{
1 Doutora em Educação. Professora da Coordenadoria de Matemática do Instituto Federal do Espírito Santo (Ifes) - Campus Vitória. Bolsista capixaba Fapes. E-mail: sandrafraga7@gmail. Orcid: https://orcid.org/0000-0002-0902-627X

2 Mestre em Educação. Doutoranda da Universidade Federal de Santa Maria. E-mail: andressawm@yahoo.com.br. Orcid: https://orcid.org/ 0000-0002-6777-5738.

3 Doutora em Educação. Professora da área de Educação Matemática do Departamento de Metodologia de Ensino do Centro de Educação da Universidade Federal de Santa Maria (UFSM). E-mail: anemari.lopes@gmail.com. Orcid: https://orcid.org/0000-0002-4636-9618.
} 


\section{RESUMEN}

Este trabajo discute el proceso formativo docente con base en el análisis de acciones, abarcando ubicación y percepción del espacio en un grupo de Guardería II. Las acciones resultan de un curso de extensión sobre Geometría y movimientos lógico-históricos de sus conceptos, involucrando estudiantes de grado y profesoras. Se utiliza el enfoque teórico-metodológico de la Actividad Orientadora de Enseñanza, vinculada a la teoría de la Actividad. El proceso formativo involucró estudio del movimiento lógico-histórico de los conceptos de ubicación y percepción espacial como conocimientos importantes para la enseñanza de Geometría. Se concluye que la organización de la enseñanza de Geometría para la Educación Infantil debe primar por la geometría sensorial, teniendo en cuenta la actividad principal del niño, el jugar, lo que puede ser desencadenado por medio de un movimiento que promueve el desarrollo de los niños y propicia aprendizajes al profesor. Se identifica, aún, la necesidad de discusiones acerca del estudio de conceptos geométricos para la organización de la enseñanza de Geometría en la niñez.

Palabras clave: Educación Infantil. Formación de profesores. Geometría. Actividad Orientadora de Enseñanza. Teoría Histórico-Cultural.

\section{INTRODUÇÃO}

Nas últimas décadas, presenciamos diferentes discussões sobre 0 ensino de Geometria e a relação com a formação docente. Sena e Dorneles (2013) tanto apontam essa questão como um desafio nas pesquisas que envolvem a temática quanto destacam que "persiste a falta de preparo dos professores para trabalhar com a Matemática de forma geral, especialmente a geometria" (SENA; DORNELES, 2013, p. 154). Diferentes pesquisadores ressaltam que a geometria não tem sido ensinada adequadamente nos diferentes níveis de ensino (MIGUEL; FIORENTINl; MIORIM, 1992; PAVANELLO, 1993). Esses desafios estão relacionados à formação docente, seja inicial, seja continuada, e são ampliados quando nos reportamos à formação inicial na licenciatura em Pedagogia. A partir de nossos estudos, pautados em autores como os citados anteriormente, identificamos que esses fatos influenciaram a formação de uma geração de professores que estão em sala de aula, inclusive os que ensinam matemática na Educação Infantil e Anos Iniciais do Ensino Fundamental. Algumas pesquisas, como a de Nacarato e Passos (2003) e de Sena e Dorneles (2013), comprovam que, nos últimos anos, tem ocorrido uma tentativa de resgate desse conteúdo nas aulas de matemática e em formações iniciais e continuadas, de maneira diferenciada, em especial com o uso de diversificadas tecnologias. Porém, ao trabalharmos com professores em formações iniciais e continuadas, verificamos que, apesar dos avanços, ainda temos um longo caminho a ser percorrido. Essas questões levaram-nos à necessidade de investigações e formações sobre Geometria para professores que ensinam matemática na Educação Infantil e Anos Iniciais. Em especial, discussão de conceitos relacionados às figuras geométricas e sua organização a partir da decomposição do espaço ao plano e de localização e percepção do espaço. Sempre relacionando ao processo de ensino e aprendizagem de geometria para crianças.

Essa necessidade de pesquisa sobre a formação docente e geometria configurou-se numa proposta de ação mediante uma perspectiva teórica específica que está relacionada com a Teoria Histórico-Cultural (THC) de Vigotski (1893-1934), a Teoria da Atividade (TA) de Leontiev (1903-1979) e a Atividade Orientadora de Ensino (AOE) de Moura (1996, 2001) e Moura et al. (2010). Pensar na formação docente nessa perspectiva é compreender que ela ocorre num processo que favorece

40 nome Vigotski pode ser encontrado escrito de diferentes maneiras, como Vygotsky, Vigotsky. Neste artigo, adotaremos a nomenclatura Vigotski, quando reportarmos a ele e manteremos a escrita original, quando apresentadas as referências. 
"0 coletivo como espaço de produção de conhecimento" (MORETTI; MOURA, 2010, p. 357). Nesse espaço, criam-se "condições para a atribuição de novos sentidos às ações dos professores e dessa forma, para a produção de um novo fazer docente" (idem, p. 358). Assim, por meio de discussões sobre 0 trabalho do professor, sobre o seu ensino, no nosso caso ensino de geometria, realizamos 0 processo formativo da docência.

Nesse sentido, justifica-se a importância de constituir um espaço de discussão sobre o planejamento, execução e avaliação de atividades relativas à geometria, mais especificamente quanto ao movimento lógico-histórico de conceitos, dando-se especial destaque à elaboração de situações desencadeadoras de aprendizagem (SDA) na perspectiva da Atividade Orientadora de Ensino e ao uso de recursos didáticos adequados à atividade principal dos envolvidos. Sendo assim, este trabalho é derivado da análise de um processo formativo, realizado por meio de um projeto de extensão sobre a geometria e movimento lógico-histórico de seus conceitos, durante o primeiro semestre de 2018 , fruto de uma pesquisa de estágio pós-doutoral ${ }^{5}$ de uma das autoras deste artigo. A pesquisa foi desenvolvida no Grupo de Estudos e Pesquisas em Educação Matemática (GEPEMat) na Universidade Federal de Santa Maria (UFSM). Tivemos a participação de licenciandas de Pedagogia e de Matemática, mestrandas, doutorandas e professoras ${ }^{6}$ da Educação Infantil e dos Anos Iniciais. Foram realizados dez encontros de aprofundamento do movimento lógico-histórico de conceitos geométricos e organização de SDA que foi aplicada em duas salas de aula, uma da Educação Infantil no Berçário II (crianças de 1 a 2 anos) e outra numa turma de $3^{\circ}$ ano do Ensino Fundamental. Nesses encontros estudamos o movimento lógico histórico de geometria partindo da compreensão histórica dos conceitos geométricos, do movimento de composição e decomposição e do planejamento de tarefas de ensino a serem desenvolvidas em salas de aulas das participantes. Realizamos para este artigo um recorte das ações de formação que culminaram em um trabalho sobre nexos conceituais de geometria que tratam da localização e percepção do espaço em uma turma de bebês. Nosso foco centrou-se no desafio de organizar ações que envolvessem nexos conceituais de geometria para bebês, baseando-nos em sua atividade principal, que é 0 brincar, interagir e explorar, considerando, assim, toda a especificidade dessa faixa etária. Dessa maneira, neste artigo, o objetivo consiste em discutir o processo formativo docente mediante a análise de ações do curso de extensão envolvendo localização e percepção do espaço em uma turma de Berçário II na rede municipal de ensino da cidade de Santa Maria /RS.

Para trabalharmos a formação docente nesse nível de ensino, entendemos ser preciso "[...] dimensionar 0 ensino de matemática na Educação Infantil, adequando-o às necessidades da criança para sua integração e desenvolvimento pleno juntamente com a coletividade que a acolhe" (MOURA, 2007, p. 59). Na Teoria da Atividade, Leontiev (1978) destaca a atividade principal, que é aquela que vai fazer com que 0 indivíduo desenvolva novas formações psicológicas. Segundo esse autor, a criança em idade pré-escolar, como no nosso caso, tem o brincar $^{7}$ como sua atividade principal.

De acordo com Moraes, Arrais, Moya e Lazaretti (2017, p. 355):

\footnotetext{
50 projeto pós-doutoral intitulado "Processo formativo docente em atividade de ensino e de estudo de geometria" foi desenvolvido de 20172018. Teve por objetivo geral investigar elementos que contribuem para a aprendizagem de geometria de professores e futuros professores ao elaborarem coletivamente atividades orientadoras de ensino. Agradecemos à Capes pelo financiamento da bolsa de estágio pós-doutoral e ao Programa de Pós-Graduação em Educação Matemática e Ensino de Física da Universidade Federal de Santa Maria/RS pela oportunidade da pesquisa.

6 Vamos usar, sempre no feminino, licenciadas, professoras, acadêmicas, tendo em vista que apenas mulheres participaram da pesquisa.

7 Nas traduções das obras desse autor, é mais usado o termo "jogo" para designar a atividade principal da criança. Contudo, em virtude de discussões mais recentes sobre esse assunto, pautadas em autores da Teoria Histórico-Cultural, usaremos o termo "brincar", por entendermos que ele caracteriza melhor essa atividade.
} 
A brincadeira põe em funcionamento toda uma complexidade de funções psíquicas, visto que as situações lúdicas exigem da memória, da atenção, da imaginação, do pensamento em funcionamento para que as crianças possam atuar com objetos. Exigem também argumentação para inserir o conteúdo na brincadeira. As condições, as regras fazem com que as crianças se concentrem, memorizem para garantir o êxito da situação lúdica.

Essa compreensão coloca-nos no desafio de buscar uma formação que organize situações de ensino que valorizem essa atividade principal, para que as crianças tenham condições de se aproximar de conceitos matemáticos que contribuam para o seu desenvolvimento. Além de indicar a necessidade da intencionalidade ao se planejar uma ação envolvendo brincadeiras para o trabalho com conhecimentos matemáticos. Essa organização ocorreu mediante a organização intencional de uma Atividade Orientadora de Ensino e suas situações desencadeadoras de aprendizagens num coletivo de licenciandas e professoras.

Ao tomarmos essa proposta, organizamos o texto em dois momentos: No primeiro, baseamo-nos na perspectiva histórico-cultural para a formação de professores, apresentando os pressupostos teórico-metodológicos da Atividade Orientadora de Ensino (AOE), discorrendo sobre sua estrutura e a organização de situações desencadeadoras de aprendizagem; na sequência, discutimos sobre a necessidade do estudo sobre o movimento lógico-histórico de geometria e os nexos conceituais de localização e percepção espacial; no segundo, trazemos o percurso formativo efetivado na nossa ação de extensão, analisando as ações de planejamento, desenvolvimento e avaliação da proposta e finalizamos 0 artigo com nossas considerações sobre esse processo.

\section{ATIVIDADE ORIENTADORA DE ENSINO, FORMAÇÃO DOCENTE E ENSINO DE GEOMETRIA}

Com base na compreensão de infância e criança na perspectiva da Teoria Histórico-Cultural, faz-se importante dialogar sobre os pressupostos da Atividade Orientadora de Ensino, de Moura (1996, 2001) e Moura et al. (2010) como uma proposta teórico-metodológica.

Moura (1996) compreende que o professor e estudantes têm necessidades distintas em relação ao processo de ensino e aprendizagem de matemática. A necessidade do professor é ensinar um conteúdo matemático e a do estudante é apropriar-se desse conteúdo, sua origem, sua utilização e seus procedimentos. Assim, "a atividade de ensino do professor deve gerar e promover a atividade do estudante. Ela deve criar nele um motivo especial para a sua atividade: estudar e aprender teoricamente sobre a realidade" (MOURA et al., 2010, p. 90). Para planejarmos ações, devemos considerar que a $\mathrm{AOE}$ apresenta algumas etapas características de sua estruturação metodológica, a saber: a síntese histórica do conceito, a situação desencadeadora de aprendizagem, a síntese da solução coletiva e a avaliação. Essas fazem parte da organização do ensino, e, assim, precisamos tratar delas na ação de formação que as discute. Como temos o foco no ensino e na formação dos professores que ensinam matemática, compactuamos com Moura (1996), quando explicita que

[...] a atividade que respeita os diferentes níveis dos indivíduos e que define um objetivo de formação como problema coletivo é o que chamamos de Atividade Orientadora de Ensino. Ela orienta um conjunto de ações em sala de aula a partir de objetivos, conteúdos e estratégias de ensino negociado e definido por um projeto pedagógico. Contém elementos que permitem à criança apropriar-se do conhecimento como um problema. 
E isso significa assumir 0 ato de aprender como significativo tanto do ponto de vista psicológico, quanto de sua utilidade (MOURA, 1996, p. 32).

A AOE constitui "um modo geral de organização do ensino, em que seu conteúdo principal é 0 conhecimento teórico e seu objeto é a constituição do pensamento teórico do indivíduo no movimento de apropriação do conhecimento" (MOURA et al., 2010, p. 221). É, assim, compreendida por nós como um processo dinâmico e adotada como proposta teórico-metodológica para a execução das ações: teórico na medida em que seus fundamentos, pautados na Teoria Histórico-Cultural, nos oferecem subsídios para compreender o processo de apropriação de conhecimentos por parte do professor e do aluno; e metodológico, porque nos fornece orientações de encaminhamento para sala de aula e para a produção das situações desencadeadoras de aprendizagem; neste caso, de geometria.

A Atividade Orientadora de Ensino constitui uma atividade, na perspectiva de Leontiev, e, dessa maneira, possui elementos, tais como: necessidades (de o professor ensinar e 0 aluno aprender); conteúdo (conhecimento teórico); motivos (de o professor organizar o ensino e 0 aluno apropriar-se do conhecimento teórico); e ações (do professor: definição de como trabalhar os conteúdos teóricos; e do aluno: resolução das situações propostas).

A presença desses elementos no processo formativo coletivo possibilita evidenciar a atividade principal do professor, que é a Atividade de Ensino. Moretti (2007) aponta que a formação numa perspectiva coletiva ante as demandas do trabalho docente revela desafios na escolha de estratégias e instrumentos de ensino e mobiliza a necessidade de apreender a história da matemática na abordagem dos conteúdos. A autora destaca a necessidade de realizarmos ações que propiciem mudanças na adoção de proposições de situações-problema e momentos coletivos de trabalho em sala de aula no tocante aos seus planos de ação. Além disso, Moretti (2007) ressalta que, para proceder ao processo, é necessário pensar o trabalho de ensinar momentos de estudos teóricos e práticos na formação realizada. Assim, a discussão sobre a atividade de ensino revela potencial para constituir o pensamento teórico e prático inerente ao trabalho docente e orientar a estrutura da formação continuada.

Uma formação baseada nos princípios teórico-metodológicos da AOE requer discussões sobre sua estruturação de maneira coletiva, pois essa ação estará diretamente relacionada com uma proposta que se volta para a atividade principal docente. Isso implica criar condições de aprender a síntese histórica do conceito com 0 qual se vai trabalhar. Essa compreensão ocorre mediante 0 estudo do movimento lógico-histórico do conceito, que é mais amplo do que conhecer a história do conceito: faz-se necessário conhecer a essência do objeto investigado e as necessidades humanas que levaram à criação dos conceitos. Sousa $(2018$, p. 47$)$ destaca que, "ao considerarmos a unidade dialética apresentada no par lógico-histórico do movimento do pensamento, defendemos que esse movimento, durante toda a sua existência procura, se aproximar do movimento que compõe o objeto em estudo". Compreendendo essa dialética entre o lógico e o histórico, Kopnin (1978) afirma:

Por histórico subtende-se o processo de mudança do objeto, as etapas de seu surgimento e desenvolvimento. 0 histórico atua como objeto do pensamento, o reflexo do histórico, como conteúdo. 0 pensamento visa à reprodução do processo histórico real em toda sua objetividade, complexidade e contrariedade. 0 lógico é o meio através do qual o pensamento realiza essa tarefa, mas é o reflexo do histórico em forma teórica, vale dizer, é a reprodução da essência do objeto e da história de seu desenvolvimento no sistema de abstrações. 0 histórico é primário em relação ao lógico, a lógica reflete os principais períodos da história (KOPNIN, 1978, p. 183-184). 
Embasados no estudo dialético do movimento lógico histórico dos conceitos, conseguimos compreender a sua essência, pois "a unidade entre o lógico e o histórico é premissa metodológica indispensável na solução dos problemas da inter-relação do conhecimento e da estrutura do objeto e conhecimento da história e seu desenvolvimento" (KOPNIN, 1978, p. 186). No processo formativo, portanto, precisamos criar espaços de estudos dos conceitos nessa perspectiva dialética organizando modos de fazer o ensino. Segundo Borowsky et al. (2016, p. 748-749):

Pensar 0 ensino de matemática na Educação Infantil nesta perspectiva implica, antes de tudo, em compreender que aprender é parte constitutiva do ser humano e a infância é um campo de possibilidades de aprendizagem matemática. A criança, desde o seu nascimento, é capaz de aprender e de relacionar-se ativamente com tudo e todos que estão ao seu redor.

Quando pensamos no caso da geometria, compreender esse movimento nem sempre é tarefa fácil, visto que é necessário apreender o processo humano de construção de seus conceitos e apresentar propostas de ensino como "um modo de organização que rompe com a ideia de trabalhar apenas nomenclaturas e fórmulas de área, perímetro e volume" (SILVA; LOPES, 2019, p. 218). No caso da Educação Infantil, é além disso, visto que não se trabalha com fórmulas e sistematizações, mas trata-se de compreender quais conceitos geométricos, ao serem explorados com as crianças, podem contribuir no seu desenvolvimento.

Com base nos estudos sobre geometria, na perspectiva do que até aqui apresentamos, identificamos a localização e a percepção espacial como nexos conceituais importantes para serem trabalhados desde a Educação Infantil, visto que são conceitos necessários ao desenvolvimento dos indivíduos. Os nexos conceituais são entendidos como os aspectos que revelam a essência do conceito, em seu aspecto tanto histórico como lógico. Para Petrovski (1980, p. 223), percepção é "a imagem dos objetos ou fenômenos que se cria na consciência do indivíduo e atua diretamente sobre os órgãos dos sentidos, processo durante 0 qual se realiza 0 ordenamento e a associação das distintas sensações em imagens integrais de coisas e atos". Esse autor indica que a constância da percepção é uma condição necessária à vida e à atividade humana, pois ela nos ajuda a movimentar e interagir com o mundo. Nesse sentido, é importante realizarmos ações que ajudem as crianças a desenvolver sua percepção do espaço, tanto de objetos no espaço como deles próprios no espaço. Por meio da percepção, as pessoas formam uma imagem adequada do objeto (PETROVSKI, 1980). Daí a relevância do trabalho com percepção por parte das crianças, como forma de organizar suas imagens mentais dos objetos que estão ao seu redor. Mas isso não acontece de forma espontânea, pois o fato de elas estarem em contato com objetos físicos não garante que isso ocorra. Para isso acontecer, é necessária uma orientação acerca das ações específicas com o objeto, e, nesse sentido, cabe ao professor agir intencionalmente para promover tais situações. 0 autor ainda destaca que experiências que envolvem mais de um sentido na percepção, por exemplo envolvendo mãos e olhos, favorecem na percepção dos objetos e é preciso organizar ações para que os alunos tenham uma percepção voluntária (não espontânea) ante a observação.

Petrovski (1980, p. 245) ressalta que a percepção espacial é essencial para a interação da pessoa com o meio em que vive e "é condição indispensável para orientar nele". Ele afirma que a percepção espacial é "a representação do espaço objetivamente existente e inclui a percepção da forma, o tamanho e a localização dos objetos entre si, seus relevos, a distância e a direção em que se encontram". 
Ao analisarmos o movimento histórico, notamos que a humanidade, desde os seus primórdios, sempre precisou organizar essa percepção para reconhecer o meio em que estava inserido e conseguir localizar-se, percorrer ou determinar distâncias, conhecer formas, tamanhos, profundidade e distância entre objetos e desenvolver seu pensamento quanto ao conhecimento do que existia e, posteriormente, do que construiu desde sua ação sobre a natureza. Petrovski (1980) destaca essas ações e a necessidade humana de desenvolver percepções de tempo e movimento.

Moura et al. (2018) apontam que a geometria proporcionada por meio dos sentidos é denominada geometria sensorial, aquela que é obtida por meio das interações dos sujeitos com o mundo. Assim, a percepção espacial está diretamente relacionada com essa geometria sensorial. Na história, notamos que, desde o homem do período neolítico, existia a necessidade de noções de localização espacial, de memória topográfica e reconhecimento das formas da natureza por meio da percepção espacial. Nesse sentido, Moura et al. (2018, p. 8) afirmam que "foi por meio da utilização dos sentidos que [0] homem primitivo veio a elaborar o que denominamos de geometria sensorial".

Quando a humanidade deixa de ser nômade e inicia a construção de abrigos, suas necessidades de percepção espacial e localização ampliam-se. 0 homem transforma-se em coletor e depois em produtor, o que faz surgir novas necessidades de interação com o mundo. Segundo Moura e Lanner de Moura (1997, p. 1), o ponto de referência de organização do espaço a princípio é o próprio corpo, depois existe a relação entre os objetos. Conceitos como longe, perto, em cima, embaixo, atrás, enfrente, alto, baixo, dentro, fora, entre outros, foram modificando-se desde a ampliação das percepções espaciais e da localização.

Segundo Bishop (1999, p. 48), "todas as sociedades desenvolveram métodos mais ou menos sofisticados para codificar e simbolizar o entorno espacial". Ele ainda afirma que, apesar de não ser tão estudada como 0 ato de contar nas diferentes culturas, a questão da localização é importante para as noções geométricas e estão presentes nas mais diversas culturas. Essa necessidade foi modificando-se ao longo da história, mediante a interação da pessoa com o mundo e com outros. Aprender a se localizar faz parte de um desenvolvimento cognitivo necessário a todos, e as crianças precisam apropriar-se desse conceito para melhorar sua interação com o meio em que está inserida.

Após 0 estudo do conceito, seguindo a proposta da AOE, no processo formativo nos propomos a organizar - de forma coletiva - a situação desencadeadora de aprendizagem, que envolve ações intencionais do docente, seguidas de operações que levem o aluno a colocar-se na necessidade de realizá-las, criando o motivo de busca de soluções relacionadas ao conteúdo proposto que promovam funções psíquicas. Entendemos que, quando esse processo faz parte da formação docente, "[...] a atividade orientadora de ensino se converterá em atividade de aprendizagem do professor, a partir do momento em que este se constituir como 0 sujeito da atividade, como aprendente" (LOPES, 2009, p. 101). À vista disso, vislumbramos a relevância da formação ocorrer num processo coletivo e reflexivo, analisando os diferentes momentos do planejamento intencional das ações de ensino. Esse caminho foi percorrido no nosso processo formativo que está descrito no segundo momento deste artigo.

\section{O PROCESSO FORMATIVO DOCENTE A PARTIR DAS AÇÕES DESENVOLVIDAS NO BERÇÁRIO II}

Nosso objetivo visa discutir o processo formativo docente com base na análise de ações desencadeadas no curso de extensão, envolvendo localização e percepção do espaço em uma turma de Berçário II na rede municipal de ensino da cidade de Santa Maria/RS. Para isso, fez-se necessário realizar um estudo e apropriar-se de conceitos sobre o que versa a geometria. 
Conforme comentado, realizamos um projeto de extensão em um curso que teve por objetivo estudar o movimento lógico-histórico de conceitos geométricos, para organizar ações relativas aos conteúdos estudados, dando destaque a situações desencadeadoras de ensino que se aproximam da perspectiva da Atividades Orientadoras de Ensino e ao uso de recursos didáticos. As licenciandas e professoras envolvidas nessa ação foram informadas do estudo do qual estavam participando e, depois de terem estado cientes das questões éticas da pesquisa, assinaram o Termo de Consentimento Livre e Esclarecido (TCLE). 0 curso ocorreu no primeiro semestre de 2018 e contou com a participação de duas licenciandas de Pedagogia, uma de matemática (que já era licenciada em Pedagogia) e cinco professoras licenciadas em Pedagogia e uma em Matemática, das quais apenas uma atuava na Educação Infantil. Destacamos que as professoras participantes também faziam mestrado ou doutorado. Embora o curso em sua totalidade tenha envolvido estudos e ações em diferentes anos, selecionamos, neste artigo, dados específicos das duas professoras que atuaram na Educação Infantil, os quais foram produzidos por meio de relatos e tarefas desenvolvidas durantes os encontros, áudios e vídeos de diferentes momentos, além de questionário online e seção reflexiva realizada no fim do curso. Para a análise dos dados, apresentamos o movimento formativo percorrido, trazendo indícios de aprendizagens das professoras sobre as ações relativas ao processo pensado para a Educação Infantil.

Num primeiro momento, estudamos alguns materiais (LIMA; MOISÉS, 2002; MOURA et al., 2018) que tratavam de conceitos de geometria a partir do movimento lógico-histórico dos conceitos. Com este estudo, identificamos que precisávamos pensar nas crianças e suas atividades e nos materiais que precisaríamos organizar para as situações desencadeadoras de aprendizagem. 0 grupo estudava geometria para a infância, compreendendo a Educação Infantil e os anos iniciais do ensino fundamental, porém, para o planejamento e promoção das ações, foi dividido em dois subgrupos, um para cada nível de ensino. Cada grupo se reuniu e planejou suas ações, e, num momento posterior, realizamos uma avaliação coletiva com todas participantes.

Ao estudamos a geometria que poderia ser trabalhada com crianças, notamos que seria preciso identificar alguns aspectos principais de conceitos geométricos. Segundo Moura et al. (2018, p. 7), podemos destacar "três momentos iniciais do desenvolvimento da geometria que consideramos imprescindíveis para o desenvolvimento do gênero humano, os quais nós os nomeamos por: geometria sensorial, geometria prática e geometria formal".

Como trabalhamos com bebês inseridos na Educação Infantil, entendemos que precisávamos atentar para a geometria sensorial, em especial a que pudesse partir de brincadeiras e jogos, atentando para a atividade principal da criança, que é o brincar. Mediante os estudos, percebemos que os nexos conceituais que poderiam ser trabalhados com crianças da Educação Infantil seriam a localização e a percepção espacial, de modo que as crianças se envolvessem no reconhecimento do espaço e do lugar que elas próprias e os objetos ocupam nesse mesmo espaço. Essa geometria sensorial pode ser percebida por meio dos sentidos, ante 0 desenvolvimento da percepção espacial, que nas crianças é ainda mais intenso, pois são curiosas e estão na fase de descoberta do mundo a sua volta. Trabalhar a geometria sensorial é envolver os sujeitos em necessidades vivenciadas pela humanidade relativas à percepção do espaço, compreensão de suas formas e tamanhos, das relações entre seus objetos. Nesse sentido, as crianças poderiam ter condições de iniciar um processo de aproximação à geometria. Moura et al. (2018, p. 7) destacam que "a geometria pode ser vislumbrada como uma forma de representação e compreensão do espaço, sendo este constituído de objetos com suas variadas formas e relações, cabendo aos sujeitos a percepção dos mesmos". Na Educação Infan- 
til, Araújo (2010, p. 164-165) destaca que se pensarmos a partir da Teoria Histórico-Cultural, "em relação à geometria, faz-se necessário considerar que a criança se apropria do espaço a partir de seu próprio corpo e de seus deslocamentos, construindo noções geométricas gradativamente mais complexas". Organizamos o esquema a seguir (fig. 1), que apresenta uma síntese desses estudos e relaciona os nexos conceituais de percepção espacial e localização, apresentando a relação dialética entre eles e sua importância para a compreensão do espaço.

Figura 1 - Esquema síntese dos nexos conceituais de percepção espacial e localização

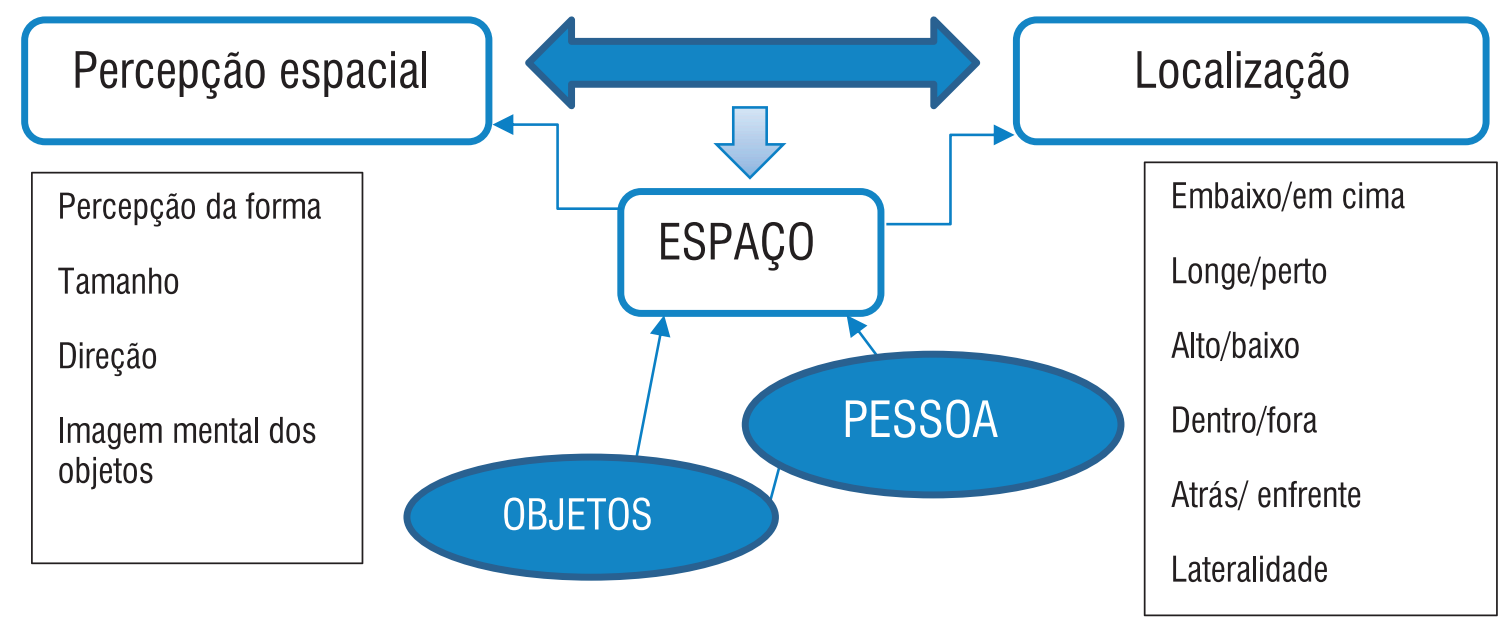

Fonte: Dados da pesquisa

Desde 0 nascimento, as pessoas já interagem com o espaço em que vivem. Precisam organizar-se e locomover nesse espaço e compreender os objetos e outras pessoas que também nele estão. Em um primeiro momento, essa compreensão ocorre de maneira natural, por meio de conhecimentos empíricos. Porém, na escola os professores intencionalmente precisam criar condições para que essa compreensão se amplie, contribuindo para que as crianças se apropriem desses conceitos, para interagir e se locomoverem no mundo que as cerca (PETROVSKI, 1980). Com base nesses estudos e determinação dos nexos conceituais que precisávamos trabalhar, passamos ao segundo momento, quando realizamos o planejamento de situações desencadeadoras de aprendizagens, para trabalhar com geometria sensorial, mais especificamente sobre os nexos de percepção espacial e localização. Para isso, precisamos pensar na condição das crianças, uma vez que elas aprendem de diferentes maneiras, mas, para que essas aprendizagens aconteçam, é necessário organizar intencionalmente 0 espaço, o tempo, as relações e as ações que promovam as funções psicológicas superiores. Mello (2017, p. 43), destaca que

[...] as crianças aprendem desde que nascem, mas aprendem de um jeito próprio em cada idade. Quando olhamos para o bebê procurando o que ele é capaz de fazer - em vez de olhar apenas aquilo que ele ainda não consegue fazer -, percebemos como ele se relaciona com o mundo por meio do olhar, do gesto, do movimento, por meio daquilo que pega, olha, leva à boca. 0 bebê sente 0 mundo e se comunica por meio do seu corpo; suas sensações confundem percepção com emoção. Por isso é tão 
importante a forma como a pessoa adulta toca o bebê, como anuncia ao bebê sua presença e sua intenção antes de tocá-lo, de tirá-lo do berço ou do chão, de trocá-lo de ambiente, de interromper aquilo que ele está fazendo.

Em especial, tratando-se de bebês, é de extrema importância estudar e, assim, compreender 0 seu contexto educativo, saber perceber suas necessidades, o momento exato de realizar a mediação e principalmente respeitar o tempo individual de cada um. Estar com bebês em sala de aula é estar sempre atento aos seus movimentos, interesses e desinteresses. É ter um olhar sensível ao que ainda não conseguem realizar sozinhos e precisam da mediação docente. Diante disso,

[...] a criança nunca é abandonada em sua atividade: nós adultos estamos sempre por perto, num raio de escuta e visão mútuas. Nós não intervimos diretamente dirigindo a atividade e o movimento do bebê e da criança; não fazemos pelas crianças o que cabe a elas fazer para formar a percepção, a memória, a fala, o pensamento; não criamos dependência ou atitude de espera. Ao contrário, organizamos 0 ambiente para que as próprias crianças explorem o mundo ao seu redor e realizem livremente seus próprios movimentos - 0 que prepara 0 corpo para os próximos e mais elaborados movimentos -; oferecemos constantemente novas fontes de interesse para elas, apresentando novos objetos para sua exploração, explorando com elas os diferentes ambientes internos e externos da creche. Nesse sentido, nós adultos não forçamos o bebê a fazer um movimento, ou a adotar uma postura que ele não seja capaz de adotar sozinho - ou seja, não forçamos o bebê a se sentar ou a andar - mas estimulamos seu movimento livre e reconhecemos sempre verbalmente para o bebê os avanços obtidos por ele nos seus movimentos, ajudando-0 a tomar consciência de suas conquistas (MELLO, 2017, p. 47).

Pensando nisso e nos nexos que queríamos trabalhar, organizamos o ambiente/espaço para que os bebês interagissem, vivenciassem e explorassem, bem como oferecemos constantemente novas fontes de interesse com base na definição de alguns objetivos esperados: aproximar os bebês do conhecimento sobre geometria; explorar formas de deslocamento no espaço; experimentar possibilidades corporais nas brincadeiras e explorações; manipular, experimentar, arrumar e explorar 0 espaço por meio de experiências de descolamento de si e dos objetos.

Esse momento de planejamento é importante para o professor no processo formativo, principalmente quando ocorre no coletivo e é discutido na intencionalidade do ensino. Na organização de situações desencadeadoras de aprendizagem, o professor "lançará mão de instrumentos e de estratégias que lhe permitirão uma maior aproximação entre sujeitos e objeto de conhecimento" (MOURA, 1996, p. 4). Essa preocupação na organização da ação está presente na fala das professoras Helena e Aurora, ao serem questionadas quanto ao planejamento (questionário online da pesquisa ao final do curso de extensão), conforme verificamos a seguir.

Helena: os bebês são verdadeiros exploradores, então a preocupação foi de realmente proporcionar a eles momentos que pudessem explorar materiais que fossem significativos, atraentes e divertidos mas que levassem a essência de conceitos da geometria...!

Aurora: Todo esse movimento de experienciar algumas ações de exploração para então discussão, nos encaminharam a compreensão da necessidade humana em criar o conceito de geometria. 
Ao entender e se aproximar do processo lógico-histórico, nossa preocupação foi de organizar situações desencadeadoras de aprendizagem e de ensino, em que a necessidade humana se fizesse presente. Ou seja, buscamos que as crianças sentissem a necessidade em resolver a situação proposta em um movimento similar ao que o ser humano vivenciou quando desenvolveu o conceito de geometria.

Notamos que as docentes relacionaram o que foi discutido no curso sobre o movimento lógico-histórico dos conceitos com o planejamento da ação com os bebês. Isso atende ao processo formativo por meio da organização de situações desencadeadoras de ensino. Nesse sentido, "reconhecer os conceitos matemáticos como produção humana constituída historicamente a partir de necessidades sociais implica organizar o ensino, considerando esse movimento de produção e a necessidade que o moveu" (AMORIM; MORETTI, 2017, p. 197). Nessa ação, a necessidade era perceber 0 espaço e localizar-se no espaço compreendendo suas possibilidades, em relação tanto ao próprio corpo quanto aos objetos no espaço.

Para alcançarmos tais objetivos na turma do Berçário II, elaboramos três situações desencadeadoras de aprendizagem, materializadas nas seguintes questões: 1) 0 que passa por cima ou por baixo? E por dentro e fora?; 2) Será que cabe ou não cabe?; 3) Formas e formas... aonde vai cada uma? Com base nesse planejamento, no terceiro momento, as mesmas situações ocorreram em períodos diferentes, adequando aos tempos e necessidades específicas das crianças da turma e respeitando a rotina diária da escola.

Na primeira situação desencadeadora de aprendizagem - 0 que passa por cima ou por baixo? E por dentro e fora? -, montamos, no pátio da escola, um circuito que constava com os seguintes desafios: três bambolês amarrados um ao lado do outro (fig. 2), no intuito de que os bebês passassem por dentro e fora deles; ainda nos bambolês fixados em um canto, deixamos à disposição das crianças bolas para que pudessem arremessar por dentro do contorno do bambolê; brincando no escorregador também foi uma das ações em que as professoras puderam realizar a mediação nas questões relacionadas ao subir e ficar em cima e descer e ficar em baixo, entre alto e baixo; brincadeiras com corda amarrada em dois brinquedos foram utilizadas para que os bebês passassem por baixo dela, e as crianças que se sentissem seguras poderiam tentar passar por cima; a intenção foi que elas tivessem de modificar sua postura, para superar obstáculos, abaixando ou levantado a perna. Aproveitamos um túnel móvel, de passar por dentro (fig. 3), em que a criança entrava nele e dele saía, escondendo-se e engatinhando. Também foram incentivadas a jogar a bola por dentro do túnel. Aproveitamos ainda outros brinquedos presentes no pátio, como traves de futebol infantil, para trabalhar com bolas dentro e fora, atrás e em frente.

Figura 2 - Bambolês organizados no circuito.

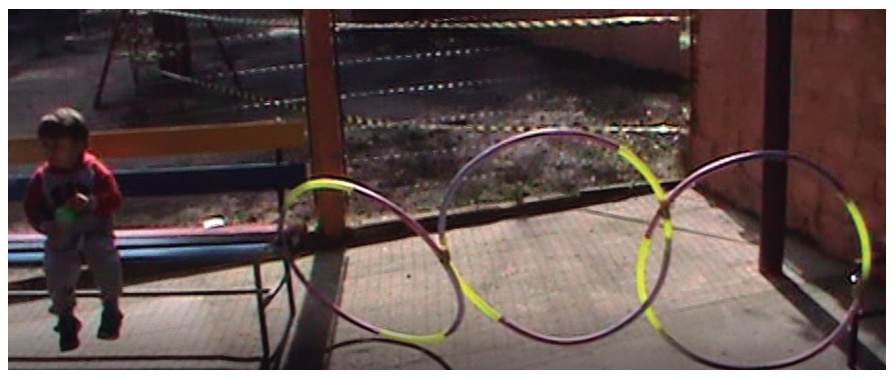

Fonte: Acervo da pesquisa.
Figura 3 - Brinquedos no pátio.

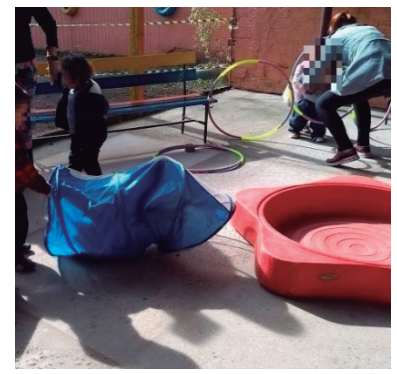

Fonte: Acervo da pesquisa. 
Havia, nesse espaço do pátio, um objeto em formato de estrela (fig. 4), que inicialmente não levamos em conta para o circuito. Entretanto, no decorrer da tarde, a professora sentou-se nesse objeto com uma criança no colo, e os outros bebês começaram a se aproximar querendo ficar perto. Nesse momento, ela começou a dialogar: "Quantos bebês cabem aqui dentro? Quais colegas estão dentro da estrela com a professora? Quais colegas estão fora da estrela? Será que cabe mais alguém aqui com a profe?"

Figura 4 - Brinquedos aproveitados do pátio.

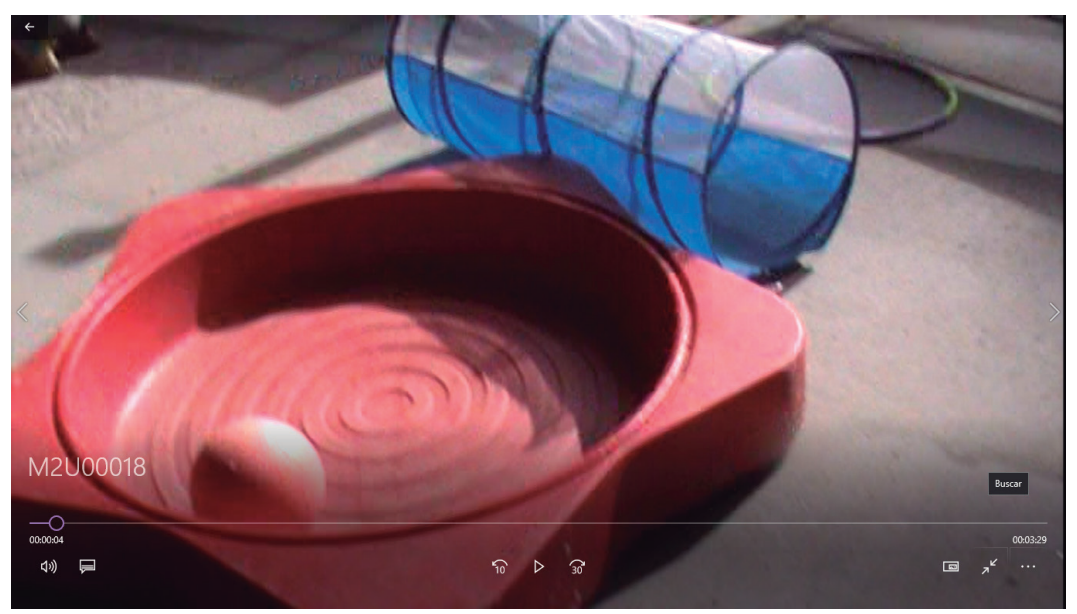

Fonte: Acervo da pesquisa.

Posteriormente essas situações foram discutidas no coletivo. Helena era a professora titular da turma do berçário e, ao ser indagada sobre uma situação que chamou sua atenção durante as ações na escola, ela pontuou: "A possibilidade da geometria estar diariamente ligada aos bebês, nas simples ações de brincar direcionada com eles com caixas de entrar e sair, no escorrega subir e descer, etc." Percebemos, em sua fala, que a participação no curso a fez perceber que ações que já realizava rotineiramente poderiam ser utilizadas de maneira intencional e que utilizava linguagem matemática adequada trabalhada no curso para trabalhar os nexos conceituais geométricos que estávamos discutindo. Isso corrobora Moura (2001), Moretti (2007) e Lopes (2009), quando destacam o fato de a formação gerar necessidade de repensar a ação de ensino, gerar mudança de qualidade na atividade principal docente.

Na segunda situação desencadeadora de aprendizagem - Será que cabe ou não cabe? -, brincamos, exploramos caixas de papelão. Organizamos lugares com diferentes caixas de papelão de diversos tamanhos: um cantinho continha apenas caixas grandes e pequenas; 0 outro, caixas de papelão com brinquedos espalhados perto, ao redor. A partir disso, foi perguntado aos bebês em qual caixa determinado brinquedo caberia. Foi deixado livre para que cada bebê experimentasse as possibilidades. As professoras iam apenas mediando a interação dos bebês com os objetos e provocando-os com perguntas e falas. Alguns empilharam caixas; outros colocaram o máximo de brinquedos dentro que conseguiram; outros entraram nas caixas e não deixavam colocar brinquedos dentro; alguns aceitavam pegar ursos de pelúcia até certo momento em que viam que não havia mais espaço suficiente. Também brincamos com a comparação de brinquedos grandes e pequenos nessas caixas. 
Ainda, em uma interação de uma professora com um bebê, ele tentava colocar um urso de pelúcia dentro de um ônibus de brinquedo. Apesar de termos pensado inicialmente somente nas caixas, aproveitamos a oportunidade de envolvimento da criança e sua interação com o brinquedo para realizar a mediação. 0 urso era grande para "caber" dentro do ônibus. A professora perguntava: "Você colocou o urso no ônibus? Mas a cabeça dele está do lado de fora. Será que cabe dentro do ônibus? Tenta colocar". A criança tentava trocar a posição do urso, mas sempre ficava parte para fora do ônibus. Ela continuava perguntando se estava dentro do ônibus, e 0 bebê tentava mudar a posição sem sucesso. Depois de algumas tentativas, ele pegou outro objeto menor, uma tartaruga de pelúcia, retirou o urso e colocou a tartaruga dentro do ônibus de brinquedo. Quando percebeu que não tinha ficado nenhuma parte do brinquedo para fora apontou e olhou para a professora com um semblante de alegria por conseguir realizar a ação. Como lidamos com bebês, nem sempre eles se expressavam oralmente, mas utilizam-se do corpo inteiro com olhares, apontando e indicando com gestos. Além disso, verificamos como a ação e mediação docente são importantes, pois a professora conseguiu, por meio da brincadeira, realizar um diálogo intencional relacionado ao conceito que queria trabalhar.

Essas diferentes ações materializaram nossas perspectivas de que é possível organizar situações desencadeadoras de aprendizagem, para trabalhar geometria com bebês. A seguir, trazemos uma fala de Aurora (questionário online), que destaca essas possibilidades de ação.

Aurora: Acho que antes de destacar situações, fica a questão: que geometria pode ser ensinada aos bebês? o que eles têm condição de aprender? serão situações de ensino ou aprendizagem? Foram esses questionamentos que nos fizeram entender que a relação dos bebês com a geometria estava na sua relação corpo e espaço. Ao desenvolver as atividades na escola consegui perceber e identificar a potencialidade dos bebês em se aproximar do conceito científico, e o quanto na fase de desenvolvimento deles, o par visão e manipulação se faz presente. E é isso que pode ter o professor como ponto de partida quando pensa no trabalho de geometria com os bebês. Além disso, eles mostraram possibilidades que não havíamos pensando como possiveis na atividade do circuito e na atividade com as caixas.

Notamos que, ao participar das ações desenvolvidas no curso e ao ser desafiada a pensar em tarefas para trabalhar alguns conceitos geométricos com bebês, a professora Aurora se colocou como sujeito aprendente, corroborando o que Lopes (2009) destaca. Além disso, fez-se necessário organizar a SDA com base no estudo do movimento lógico-histórico do conceito de geometria que queríamos trabalhar com os bebês e com a atividade própria da criança nessa idade. Essa interação tornou-se movimento de mudança da qualidade da atividade docente em sua prática (AMORIM; MORETTI, 2017).

$\mathrm{Na}$ terceira situação desencadeadora de aprendizagem, "Formas e formas... onde vai cada uma?", montamos dois cantinhos, e o primeiro continha uma caixa de papelão pendurada por um fio (fig. 5), na qual havia recortes de círculos de diferentes tamanhos. Disponibilizamos diferentes tamanhos de bolas: bola grande, bola de futebol, bolinhas de plástico, bolas de soprar. Os bebês puderam jogar as bolas para dentro da caixa por meio do círculo que consideravam que a bola iria passar (fig. 6). 
Figura 5 - Caixa pendurada - encaixe de bolas. Figura 6 - Crianças encaixando as bolas.

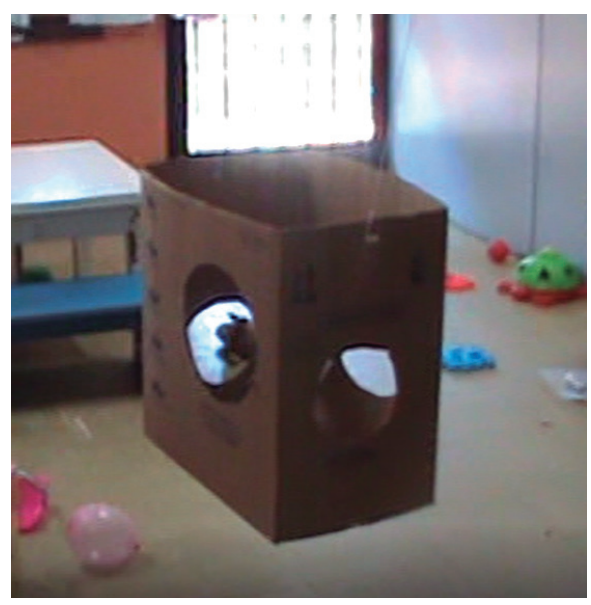

Fonte: Dados da pesquisa.

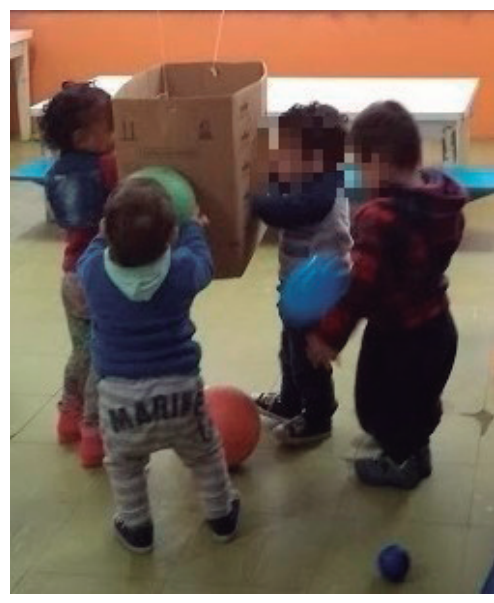

Fonte: Dados da pesquisa.

Num momento inicial, deixamos os bebês livres e observamos que as bolas pequenas foram mais fáceis porque cabiam em todos os buracos, mas a dificuldade começou quando tentavam encaixar as bolas maiores, pois precisavam procurar o buraco por qual a bola dava para passar. Notamos que alguns circulavam a caixa em busca da passagem para a bola, enquanto outros tentavam jogar a bola por cima da caixa, pois viam que era também uma possibilidade. Helena se aproximou e começou a conversar com os bebês, perguntando se cabia a bola, comentando para procurar outro, apontando que tinham tamanhos diferentes. Essa interação com a professora foi no sentido de estimulá-los a procurar outro espaço para passar a bola. E eles responderam bem a essa interação, pois rodeavam a caixa buscando o local que cabia a bola.

0 segundo cantinho tinha as caixas das formas (fig. 7), imitando aqueles brinquedos prontos de encaixe. Confeccionamos duas caixas de papelão com recorte de várias formas e disponibilizamos junto dos blocos lógicos, para que explorassem e encaixassem a forma na respectiva abertura, guardando a pecinha "dentro" da caixa. Nosso objetivo era trabalhar a questão do tamanho e da percepção da forma. Notamos que essas ações envolveram os bebês, que circulavam entre as possibilidades (fig. 8).

Figura 7 - Caixa com recortes de formas. Figura 8 - Crianças interagindo com as caixas.

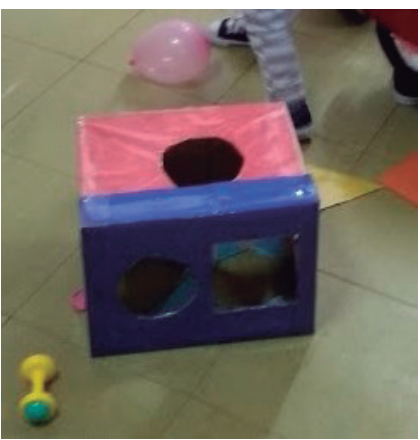

Fonte: Dados da pesquisa.

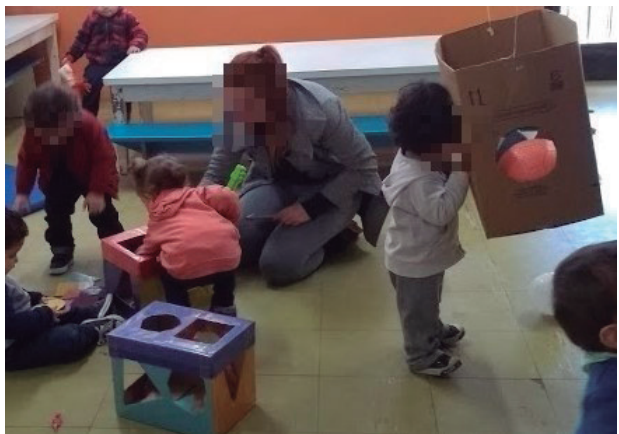

Fonte: Dados da pesquisa. 
Notamos que tanto a liberdade dada aos bebês para brincar com as caixas quanto a interação com as crianças foram importantes nesse momento. Observamos como as crianças realizavam a interação e percebemos diferenças entre os seus conhecimentos e suas maneiras de organizar os objetos. Algumas só queriam colocar as peças dentro da caixa, que foi um dos comandos, sem se preocuparem com as formas, e buscavam maneiras de fazer isso, algumas vezes até levantando a tampa da caixa e colocando as formas dentro dela. Outras crianças buscavam pelo buraco que permitia 0 encaixe. A professora Aurora destacou algumas dessas diferenças em sua reflexão sobre situações que lhe chamaram a atenção na efetivação da ação.

Aurora: Entre as situações, quando desenvolvemos ações envolvendo formas geométricas, não tínhamos como intenção abordar questões de nomenclatura, pois nosso objetivo estava em aproximá-los da questão "será que cabe? onde que cabe?" e uma menina, veio com algumas peças e disse: quadrado. Ela empilhou as peças com forma quadrangular e triangular e disse quadrado, tentou sobrepor a essas peças a peça de forma circular, observou, não disse nada, retirou a peça mantendo as anteriores e disse novamente, quadrado. Essa situação afirma que os bebês sim, têm potencialidade, de se aproximar do conhecimento científico e do pensamento geométrico, mesmo sem falar convencionalmente. Ou seja, a observação e manipulação das peças são próximas do movimento de elaboração do conceito, indicando que o conceito é histórico e que organizar o ensino com esta intencionalidade é proporcionar o desenvolvimento das funções psicológicas superiores, desde o berçário.

Essa fala apresenta uma discussão sobre nossa apreensão em propor uma SDA com bebês, pois não sabíamos se conseguiríamos trazer aspectos relativos aos estudos que havíamos realizado. Isso ocorreu no processo de formação coletiva, o que comprova o que outras ações já destacaram: "na (re)organização coletiva de suas ações, os professores atribuíram novos sentidos às próprias ações, à mediação e à escolha de instrumentos, apropriando-se das formas de realização colaborativa da atividade de ensino" (MORETTI; MOURA, 2010, p. 357).

Num quarto momento, realizamos uma sessão reflexiva com todas as participantes envolvidas no curso de geometria. Destacamos o debate que tivemos em relação ao que foi feito com os bebês. $\mathrm{Na}$ transcrição, ampliamos e trazemos a fala de outras participantes, por entendermos que contribuíram para pensar nas ações e nos nexos conceituais de percepção espacial e localização. A seguir, apresentamos alguns questionamentos sobre esses nexos conceituais e aprendizagens com base no movimento formativo de que participaram.

Pesquisadora: E com os bebês, sobre a localização?... primeiro a gente, como a gente pensava a localização? A gente já pensava a questão da localização enquanto geometria, ou não? Porque todo mundo sabia que já trabalhava dentro-fora, embaixo-em cima com bebês. Mas sabiam que isso era geometria e que isso estava relacionada com geometria?

Participantes: não.

Louise: E nem a localização, porque a gente, no clube... 
Elisa: Teve um fascículo do clube 8 que trabalhava

Louise: Lembra que eu, tu e Frida, a gente discutia: mas como assim? A gente discutia. Mas a gente não conseguia enxergar a geometria na localização. Tanto que em uma das reuniões a gente levou esse questionamento, como, qual a relação...

Elisa: A gente não conseguia enxergar isso. Antes disso, por ser anterior, a atividade do mapa..., o mapa anterior, a localização, porque...

Aurora: Mas só quando a gente foi... planejar para a escola, para os bebês, aí eu consegui. Eu nunca tinha pensado nesta perspectiva, mesmo que eu já tinha trabalhado com os bebês. Pensar a geometria nesta perspectiva que a gente abordou lá na turma da Helena, a questão do lugar em que a criança ocupa no espaço, não como geometria. Eu acho que foi a partir desse movimento do curso que me possibilitou enxergar essa potencialidade dos bebês de aprender. Tanto que eles nos mostraram coisas que não tínhamos planejado: em termos de localização, do que cabe no espaço e não cabe, a manipulação das formas. Por exemplo, eu me lembro que uma menina da sala da Helena, ela veio... a gente entregou as formas das figuras geométricas, mas não com a intenção deles saberem o que se aproxima do quadrado, do retângulo, não era o objetivo, mas o que cabia dentro daquelas caixas com os cortes no mesmo formato das peças. Aí uma menina veio e trouxe uma peça com a forma de um triângulo e outra de um quadrado. E aí ela disse: "Quadrado". Eu disse: "o quê?", ela disse: "quadrado". Aí ela sentou e empilhou. Colocou o quadrado e em cima sobrepôs a peça em forma de triângulo. E ela disse: "quadrado". Aí ela pegou a forma do círculo e empilhou em cima e ela ficou olhando. Daí ela retirou o círculo e disse: "quadrado". o círculo ela não aceitou como categoria "quadrado". Mas agora eu fiquei pensando, né, como que é visivel chegar nesse movimento lógico histórico do conceito. 0 homem também só manipulava e enxergava as formas a partir desse par, enxergar a peça e manipular para perceber o que faz com que as peças sejam diferentes. 0 quanto isso mostra que eles têm potencialidade de aprender conhecimentos científicos. E o quanto isso vai fazer diferença depois. Enquanto lógica do pensamento.

Helena: Quanto às atividades com os bebês, para mim não foi dificultoso montar essas atividades, até porque eu já trabalhava com algumas dessas, desses conceitos, mas eu não enxergava eles como nexos da geometria. Sim matemáticos, mas não geometria. Não fazendo ligação com a geometria.

Identificamos nas diferentes falas a necessidade de as professoras e futuras professoras se apropriarem dos conceitos que precisam trabalhar em sala de aula. Notamos que, ao discutirmos 0 movimento lógico-histórico dos conceitos geométricos, possibilitamos às participantes novas apropriações, mas essas situações de aprendizagem fizeram mais sentido quando perceberam a necessidade de planejar ações de ensino. Uma questão a ser destacada é a importância de o professor estar atento aos alunos, neste caso, os bebês. Os resultados corroboram análises de Moraes et al. (2017, p. 366), quando afirmam que

\footnotetext{
8 As participantes já tinham vivenciado outra experiência com estudo de conceitos e planejamento de ações no Clube de matemática. A situação indicada se trata de um material produzido projeto de pesquisa em rede intitulado "Educação Matemática nos Anos Iniciais do Ensino Fundamental: Princípios e Práticas da Organização do Ensino" (PPOE), viabilizado pelo Programa Observatório da Educação (OBEDUC) da Coordenação de Aperfeiçoamento de Pessoal de Nível Superior (CAPES). 0 projeto organizado pela USP com quatro núcleos que estavam dispostos da seguinte maneira: dois na Universidade Estadual de São Paulo - USP - um na Faculdade de Educação de São Paulo e outro na Faculdade de Filosofia, Ciências e Letras de Ribeirão Preto; um no Centro de Educação da Universidade Federal de Santa Maria - UFSM e, 0 quarto no mestrado em Educação em Ciências e Matemática na Universidade Federal de Goiás - UFG). 0 núcleo de Santa Maria ficou responsável por estudar e desenvolver o material sobre números e operações. 0 material que as participantes comentam se refere ao ebook de geometria desenvolvido pelo grupo de Goiás. 0 material final pode ser obtido no site: http://www.labeduc.fe.usp.br/?post_type=labs\&p=1295.
} 
[...] é essencial que as ações de ensino sejam direcionadas para que as crianças se apropriem dos conceitos matemáticos na relação de interdependência com os conceitos cotidianos que elas possuem. Dessa forma, propomos que o trabalho pedagógico realizado pelo professor tenha como ponto de partida o ensino de conceitos matemáticos considerados como uma produção humana diante das necessidades de melhorar as condições de vida ao longo da história. É necessário pontuar que a base da aprendizagem desses conhecimentos na Educação Infantil está na percepção sensorial da realidade concreta, realizada por meio de ações externas.

Essa percepção sensorial da realidade concreta esteve presente em nossas ações, no que chamamos de geometria sensorial. A professora Helena destacou que ela já promovia situações semelhantes às realizadas, mas não de maneira intencional, e sim relacionando com a geometria, com os nexos conceituais de percepção espacial e localização. Compreender esses nexos como produção humana para se reconhecer e se movimentar no espaço e compreender como os objetos estão no mundo faz parte do processo de desenvolvimento do pensamento teórico, mesmo que de maneira inicial nessa idade. Ou seja, apenas as relações espontâneas das crianças com os elementos sensoriais que fazem parte do seu contexto não são garantias de aprendizagem.

Destacamos que o movimento formativo envolvendo professoras e licenciandos de Matemática e Pedagogia contribuiu para uma interação entre eles e os dados apontam indícios de ampliação nas aprendizagens de todos. 0 relato a seguir da professora Talia destaca bem esse movimento.

Talia: Apesar de minha formação ser para os anos finais do Ensino Fundamental e Ensino Médio, tenho me inserido no movimento de pensar o ensino de matemática nos anos iniciais desde 2014 e destaco que sabia que era possível ensinar geometria nos anos iniciais, mas na Educação Infantil foi algo que ainda não tinha tido a oportunidade de pensar e ao perceber que era possível fiquei bastante curiosa e encantada com as possibilidades e ideias que iam surgindo em cada encontro. Esse movimento de pensar o ensino de geometria não somente nos anos iniciais, mas também na Educação Infantil, se constituindo para nós como o ensino de geometria na infância fez com que eu estudasse mais sobre o movimento lógico-histórico e buscasse por materiais que possibilitassem essa compreensão, ao mesmo tempo em que tivemos a oportunidade de aprofundar conceitos e pensar mais sobre eles, problematizando-os.

Essa fala de Talia e os outros diálogos que trouxemos no texto ressaltam a importância de organizarmos formações docentes num processo coletivo de interação entre os participantes. Além disso, destaca-se a possibilidade de se envolverem tanto no estudo do movimento lógico-histórico da geometria quanto na sistematização de situações desencadeadoras de aprendizagens, relacionando os nexos estudados com ações de acordo com as crianças e um momento posterior de síntese coletiva sobre 0 conceito e as ações docentes. Essas ações estão de acordo com o que Lopes (2009, p. 115) enfatiza como "[...] capazes de provocar mudanças qualitativas na ação docente, indicando mobilização de conhecimentos revelados na ação de ensinar". 0 processo envolveu diferentes momentos, porém todos focalizados na atividade principal do professor, que é a atividade de ensino. 


\section{CONSIDERAÇÕES FINAIS}

Iniciamos nossas considerações salientando a necessidade de organizarmos formações iniciais ou continuadas que envolvam discussões acerca da geometria e seu ensino em diferentes níveis. Este trabalho buscou discutir o processo formativo docente com base na análise de ações realizadas no curso de extensão, envolvendo localização e percepção do espaço em uma turma de Berçário II na rede municipal de ensino da cidade de Santa Maria. Configurou-se como um movimento formativo que envolveu estudo do movimento lógico-histórico de conceitos de geometria, ações de planejamento e desenvolvimento de situações desencadeadoras de aprendizagem e síntese coletiva sobre 0 processo. Ao apresentarmos nossas ações, destacamos o papel da discussão sobre a atividade, neste caso, da Educação Infantil e a maneira como esse movimento, que ocorreu no coletivo, amplia possibilidades para a constituição do pensamento teórico e prático. As ações inerentes ao trabalho docente que envolvem estudo dos conceitos e organização de sua atividade pedagógica podem orientar a estrutura da formação docente. Como tivemos um curso com foco nessa discussão, evidenciamos a importância dos diferentes momentos deste processo e a experiência das pesquisadoras sobre 0 assunto, propiciando um aprofundamento teórico metodológico sobre conceitos geométricos.

Identificamos, com os estudos do movimento lógico-histórico dos conceitos geométricos, os nexos conceituais de percepção espacial e localização como processos históricos e humanos necessários à movimentação e localização das pessoas e identificação, compreensão e organização de objetos no mundo. Entendendo que esses nexos podem ser trabalhados com crianças desde a Educação Infantil, na perspectiva de promover o seu desenvolvimento, desde que por meio de ações intencionalmente organizadas pelo professor. Elaboramos situações desencadeadoras de aprendizagem voltadas a uma turma de berçário II. Essas SDA foram pensadas considerando a realidade dos bebês em sua atividade principal de brincar e envolvendo objetos próprios da realidade deles.

A discussão coletiva durante todo o movimento formativo contribuiu para criarmos condições para a aprendizagem docente, o que foi ressaltado no processo de organização do ensino na perspectiva da Atividade Orientadora de Ensino. Destacamos esse trabalho coletivo que permeou o processo formativo e que contribuiu para que as diferentes participantes conhecessem outras realidades e se ajudassem durante o processo. Observamos que as professoras, ao planejarem coletivamente, organizaram situações intencionais, para necessidades de resolverem os problemas sobre percepção espacial e localização. Essas ações envolveram a geometria sensorial explorada por meio dos sentidos e de brincadeiras, que iniciou um processo de aproximação aos nexos conceituais geométricos trabalhados.

Destacamos que esse modo de organização - que considera a síntese histórica do conceito, a elaboração de SDA e a síntese coletiva - age diretamente sobre o desenvolvimento dos bebês, como também contribui para que as professoras e futuros professores se apropriem de conhecimentos importantes para a sua atividade de ensino. E esse processo torna-se importante à medida que apresenta um modo de ação que reconhece conceitos matemáticos como produções humanas que podem e devem ser trabalhadas de maneira intencional, desde a Educação Infantil.

\section{REFERÊNCIAS}

AMORIM, G. M.; MORETTI, V. D. Matemática na educação infantil: contribuições da atividade orientadora de ensino para a (re)organização da prática docente. Inter-Ação, Goiânia, v. 42, n. 1, p. 194-213, jan./abr. 2017. Disponível em: http://dx.doi.org/10.5216/ia.v42i1.41860. 
ARAUJO, E. S. Matemática e Infância no "Referencial Curricular Nacional para a Educação Infantil”: um olhar a partir da teoria histórico-cultural. ZETETIKÉ, FE/Unicamp, v. 18, n. 33, jan/jun 2010, p. 137-172.

BISHOP, A. J. Enculturación matemática: la educación matemática desde una perspectiva cultural. Traducción de Genis Sánchez Barberán. Barcelona: Paidós, 1999.

BOROWSKY, H. G.; MARAFIGA, A. W.; LOPES, A. R. L. V.; TOMAZZETTI, C. M. Infância e Matemática: aprendendo sobre medidas de comprimento. Perspectiva da educação matemática, v. 9, n. 21, p. 744-764, 28 dez. 2016.

KOPNIN, P. V. A Dialética como Lógica e Teoria do Conhecimento. Rio de Janeiro: Civilização Brasileira, 1978.

LEONTIEV, A. N. 0 desenvolvimento do psiquismo. Lisboa: Horizonte Universitário, 1978.

LIMA, L. C.; MOISÉS, R. P. Uma Leitura do Mundo: forma e movimento. São Paulo: Escolas Associadas, 2002.

LOPES, A. R. L. V. Aprendizagem da docência em matemática: o Clube de Matemática como espaço de formação inicial de professores. Passo Fundo: Ed. Universidade de Passo Fundo, 2009.

MELLO, S. A. Bebês e crianças pequenininhas como sujeitos: participação e escuta. In: COSTA, S. A. da; MELLO, S. A. (Orgs.). Teoria Histórico-Cultural na educação infantil: conversando com professoras e professores. Curitiba, PR: CRV, 2017, p. 41-50.

MIGUEL, A.; FIORENTINI, D.; MIORIM, M. A. Álgebra ou Geometria: Para Onde Pende o Pêndulo? Pro-posições, Campinas, FE/UNICAMP, v. 3, n. 1 (7), p. 39-54, março 1992.

MORAES, S. P. G. de; ARRAIS, L. F. L.; MOYA, P. T.; LAZARETTI, L. M. 0 ensino de matemática na educação infantil: uma proposta de trabalho com jogos. Educação Matemática Pesquisa, São Paulo, v. 19, n. 1, p. 353-377, 2017. Disponível em: https://doi.org/10.23925/1983-3156.2017v19i1p353-377

MORETTI, V. D. Professores de matemática em atividade de ensino: uma perspectiva Histórico-Cultural para a formação docente. Tese. Faculdade de Educação da Universidade de São Paulo. Programa de Pós-Graduação em Educação, 2007.

MORETTI, V. D.; MOURA, M. O. de. A formação docente na perspectiva Histórico-Cultural: em busca da superação da competência individual. Psicologia política. São Paulo, v. 10, n. 20, p. 345-361, jul./dez. 2010.

MOURA, M. O. de. A atividade de ensino como unidade formadora. Bolema, n. 2, v. 12, p. 29-43, 1996.

MOURA, M. 0. de. A atividade de ensino como ação formadora. In: CASTRO, A. D.; CARVALHO, A. M. P. e (Org.). Ensinar a ensinar. São Paulo: Pioneira, 2001.

MOURA, M. 0. de. Matemática na Infância. In: MIGUÉIS, M. da R.; AZEVEDO, M. da G. (Orgs.). Educação Matemática na Infância Abordagens e desafios. 1. ed. Vila Nova de Gaia/Portugal: Gailivro, 2007, p. 40-63.

MOURA, M. 0. de (Org.). A atividade pedagógica na teoria histórico-cultural. Brasília: Líber Livro, 2010, p. 81-109. 
MOURA, M. 0.; ARAUJO, E. S.; RIBEIRO, F. D.; PANOSSIAN, M. L.; MORETTI, V. D. A atividade orientadora de ensino como unidade entre ensino e aprendizagem. In: MOURA, M. 0. (Org.). A atividade pedagógica na teoria histórico-cultural. Brasília: Líber Livro, 2010, p. 81-109.

MOURA, M. 0. de; LANNER DE MOURA, A. R. Matemática na educação Infantil: conhecer, (re)criar - um modo de lidar com as dimensões do mundo. Escola: um espaço cultural. São Paulo: Diadema/Secel, 1997, p. 1-25.

MOURA, M. 0. de; LOPES, A. R. L. V.; ARAÚJO, E. S.; CEDRO, W. L. (Org.). Atividades para o ensino de Matemática nos anos iniciais da Educação básica. Volume IV - Geometria. São Paulo: Labeduc, 2018. Disponível em: https://bit.ly/ 3kkqKcC. Acesso em: 20 de novembro de 2019.

NACARATO, A. M.; PASSOS, C. L. B. A geometria nas séries iniciais: uma análise sob a perspectiva da prática pedagógica e da formação de professores. São Carlos: EdUFSCar, 2003.

PAVANELLO, R. M. 0 abandono do ensino da geometria no Brasil: causas e consequências. Zetetiké, Campinas, FE/UNICAMP, v. 1, p. 7-17, março 1993.

PETROVSKI, A. Psicologia General: Manual didactico para los Institutos de pedagogia. Moscou. Rússia: Editora Progresso, 1980.

SENA, R. M.; DORNELES, B. V. Ensino de Geometria: Rumos da Pesquisa (1991-2011). REVEMAT. Florianópolis (SC), v. 08, n. 1, p. 138-155, 2013. Disponível em: https://doi.org/10.5007/1981-1322.2013v8n1p138

SILVA; S. A. F. da; LOPES, A. L. R. V. Pesquisas brasileiras sobre geometria: contribuições da perspectiva histórico-cultural. Alexandria: Revista em Educação em Ciências e Tecnologia, v. 12, n. 2, p. 215-239, novembro 2019. Disponível em: https://doi.org/10.5007/1982-5153.2019v12n2p215

SOUSA, M. C. 0 movimento lógico-histórico enquanto perspectiva didática para 0 ensino de matemática. Obutchénie: Revista de Didática e Psicologia Pedagógica, 1(4), 40-68, 2018. Disponível em: https://doi.org/10.14393/0Bv2n1a2018-3.

RECEBIDO EM: 30 jun. 2020

CONCLUÍDO EM: 03 out. 2020 